\title{
Novel insights into Fukushima nuclear accident from isotopic evidence of plutonium spread along coastal rivers
}

Olivier Evrard ${ }^{1 *}$, Fabien Pointurier ${ }^{2}$, Yuichi Onda ${ }^{3}$, Caroline Chartin $^{4}$, Amélie Hubert $^{2}$, Hugo Lepage ${ }^{1}$, Anne-Claire Pottin ${ }^{2}$, Irène Lefèvre ${ }^{1}$, Philippe Bonté ${ }^{1}$, J. Patrick Laceby ${ }^{1}$, Sophie Ayrault ${ }^{1}$

${ }^{1}$ Laboratoire des Sciences du Climat et de l'Environnement (LSCE/IPSL), Unité Mixte de Recherche 8212 (CEA/CNRS/UVSQ), 91198 Gif-sur-Yvette Cedex, France.

${ }^{2}$ CEA, DAM, DIF, 91297 Arpajon, France.

${ }^{3}$ Center for Research in Isotopes and Environmental Dynamics, University of Tsukuba, Tsukuba 3058572, Japan.

${ }^{4}$ George Lemaître Centre for Earth and Climate Research, Earth \& Life Institute, Université catholique de Louvain, Louvain-la-Neuve, Belgium.

${ }^{*}$ ) Corresponding authors (email addresses: olivier.evrard@lsce.ipsl.fr and fabien.pointurier@cea.fr).

\section{Abstract}

The Fukushima Dai-ichi Nuclear Power Plant (FDNPP) accident led to important releases of radionuclides into the environment, and trace levels of plutonium $(\mathrm{Pu})$ were detected in northeastern Japan. However, measurement of Pu isotopic atom and activity ratios is required to differentiate between the contributions of global nuclear test fallout and FDNPP emissions. In this study, we used a double-focusing sector field ICP-MS to measure Pu atom and activity ratios in recently deposited sediment along rivers draining the most contaminated part of the inland radioactive plume. Results showed that plutonium isotopes (i.e., ${ }^{239} \mathrm{Pu},{ }^{240} \mathrm{Pu},{ }^{241} \mathrm{Pu}$, and ${ }^{242} \mathrm{Pu}$ ) were detected in all samples, although in extremely low concentrations. The ${ }^{241} \mathrm{Pu} /{ }^{239} \mathrm{Pu}$ atom ratios measured in sediment deposits $(0.0017-0.0884)$ were significantly higher than the corresponding values attributed to the global fallout $(0.00113 \pm 0.00008$ on average for the Northern Hemisphere between $31^{\circ}-71^{\circ} \mathrm{N}$, Kelley, J.M.; Bond, L.A.; Beasley, T.M., Global distribution of Pu isotopes and ${ }^{237} \mathrm{~Np}$, Sci. Total. Env., 1999, 237/238, 483-500). The results indicated the presence of Pu from FDNPP, in slight excess compared to the Pu background from global fallout that represented up to ca. $60 \%$ of $\mathrm{Pu}$ in the analyzed samples. These results demonstrate that this radionuclide has been transported relatively long distances ( $\sim 45 \mathrm{~km})$ from FDNPP and been deposited in rivers representing a potential source of Pu to the ocean. In future, the high ${ }^{241} \mathrm{Pu} /{ }^{239} \mathrm{Pu}$ atom ratio of the Fukushima accident sourced-Pu should be measured to quantify the supply of continental-originating material from Fukushima Prefecture to the Pacific Ocean.

\section{Introduction}

The Fukushima Daiichi Nuclear Power Plant (FDNPP) accident that affected the northeastern part of Japan in March 2011 has led to the largest release of anthropogenic radionuclides into the environment since the Chernobyl accident in 1986. Both accidents were rated 7, the maximum on the International Nuclear and radiological Event Scale (INES). Nevertheless, the total quantities of radionuclides emitted during the Fukushima accident are estimated to correspond to 10 to $15 \%$ of Chernobyl emissions ${ }^{1}$. The emitted radionuclides mainly consisted of volatile substances, i.e. ${ }^{133} \mathrm{Xe}$, 
${ }^{132} \mathrm{Te}$, radioiodine and radiocesium. However, semi-volatile and low-volatile radionuclides (e.g., ${ }^{95} \mathrm{Nb}$, ${ }^{103} \mathrm{Rb}$ ) were also detected in the atmosphere after the accident, indicating the likely occurrence of core melting at FDNPP ${ }^{2}$. A broad meltdown of reactor cores was also suggested by modeling studies relying on radionuclide records available from International Monitoring System (IMS) of the Comprehensive Nuclear Test-Ban-Treaty Organization ${ }^{3}$.

Most studies that aimed at identifying the emitted radionuclides and tracking their fate in the environment focused on gamma-emitting substances, particularly ${ }^{134} \mathrm{Cs}$ and ${ }^{137} \mathrm{Cs}$, because of their high abundance and their relatively long half-lives ${ }^{4}$. These substances mainly represent a risk for external exposure of local populations and biota. The presence of alpha-emitters and particularly of long-lived plutonium isotopes would present an additional risk for internal exposure ${ }^{5}$. Although the literature is conflicting on the potential volatilization of actinides in the physico-chemical conditions that prevailed at FDNPP , the presence of plutonium with ${ }^{238} \mathrm{Pu} /{ }^{239+240} \mathrm{Pu}$ activity ratios significantly higher than the ratio measured from plutonium global fallout $\left(\sim 0.03^{7,8}\right)$ in the region was demonstrated in six soil samples analyzed under the authority of $\mathrm{MEXT}^{9}$. Moreover, two recent studies ${ }^{10,11}$ showed that the average of these measured ${ }^{238} \mathrm{Pu} /{ }^{239+240} \mathrm{Pu}$ activity ratios in surface soils at the source correlated well with the model estimates of the spent-fuel inventory from reactors Units 1 and 3, and thus concluded that plutonium was released into the local environment during the venting of these reactors. Plutonium is generally produced in reactor fuel as a mixture of isotopes, among which a dominance of ${ }^{239} \mathrm{Pu}\left(\mathrm{T}_{1 / 2}=24100\right.$ years) is generated by neutron capture in ${ }^{238} \mathrm{U}$ and subsequent $\beta$-decay. When fuel elements containing ${ }^{239} \mathrm{Pu}$ are left in the reactor, they are exposed to further neutron capture, and isotopes with higher mass, i.e. ${ }^{240} \mathrm{Pu}\left(\mathrm{T}_{1 / 2}=6560\right.$ years $),{ }^{241} \mathrm{Pu}\left(\mathrm{T}_{1 / 2}=\right.$ 14.325 years), and ${ }^{242} \mathrm{Pu}\left(\mathrm{T}_{1 / 2}=3.76 \times 10^{5}\right.$ years), are produced ${ }^{14}$. Several authors ${ }^{6,10,12}$ provide estimations of the Pu isotopic activities present in the nuclear fuel of FDNPP reactors and spent fuel storage pools (SFSPs) at the time of the accident. Based on those estimations, it is possible to reconstruct the isotopic composition of the Pu that was potentially emitted by the three damaged reactors and the SFSPs. Zheng et al. ${ }^{13}$ also provide estimation of the released Pu isotopic composition from an analysis of litter and surface soil samples. The Pu isotopic ratios characteristic of the three damaged reactors at the time of the accident documented in those studies are compiled in Table S1.

As plutonium isotopic atom and activity ratios provide a powerful tool to quantify those sources and to discriminate between plutonium originating from various past nuclear atmospheric weapon tests (referred to as 'global fallout') and local fallout characterized by significantly different signatures, it is of obvious interest to measure as many Pu isotopic abundances as possible with the highest achievable precision. To this end, the use of mass spectrometry techniques (TIMS or ICP-MS) can provide a more detailed isotopic picture of the Pu detected in the analyzed samples than standard alpha spectrometry techniques, which are not able to differentiate between ${ }^{239} \mathrm{Pu}$ and ${ }^{240} \mathrm{Pu}$, nor to measure ${ }^{241} \mathrm{Pu}^{14}$. Furthermore, analytical techniques associated with very low detection limits (like for instance sector-field ICP-MS) should be used, as the presence of ${ }^{239+240} \mathrm{Pu}$ in very low activity concentrations (typically in the tens of $\mathrm{mBq} / \mathrm{kg}$ to the $\mathrm{Bq} / \mathrm{kg}$ range) had been reported in the few available studies conducted in the Fukushima Prefecture by $2013^{14,15}$. Several Pu isotopic measurements conducted on soil samples collected in the vicinity of Fukushima using mass spectrometry have already been published, and ${ }^{240} \mathrm{Pu} /{ }^{239} \mathrm{Pu},{ }^{241} \mathrm{Pu} /{ }^{239} \mathrm{Pu}$ and ${ }^{241} \mathrm{Pu} /{ }^{239+240} \mathrm{Pu}$ ratios higher than the global fallout signature were measured by ICP-MS in one soil and two litter samples collected within the 20 to $30 \mathrm{~km}$ zone around FDNPP ${ }^{15}$. Furthermore, a ${ }^{240} \mathrm{Pu} /{ }^{239} \mathrm{Pu}$ ratio higher than the global fallout value was found in a river water sample collected in Abukuma River ${ }^{16}$. A recent 
study based on measurements of ${ }^{238} \mathrm{Pu} /{ }^{239+240} \mathrm{Pu}$ activity ratio in soils combined with analysis of ${ }^{240} \mathrm{Pu} /{ }^{239} \mathrm{Pu}$ atom ratio in a set of nine roadside dust samples (associated with radioactive dose rates higher than $100 \mu \mathrm{Sv} \mathrm{h}^{-1}$ measured at contact, and referred to as 'black substances' by the authors) and litter samples demonstrated the presence of Pu of FDNPP-origin in material collected in the vicinity of the power plant (i.e., in Futaba, Namie, Okuma municipalities) as well as in litate-Mura and Minamisoma City (i.e., outside of the 20-km exclusion zone, to the northwest of FDNPP) ${ }^{17}$. In contrast to observations made on the continent, Pu originating from Fukushima FDNPP was not detected in the marine environment ${ }^{19,19}$.

However, the fate of this plutonium in the environment remains poorly documented. As recent publications demonstrated the spread of Fukushima fallout from the main inland contamination plume including litate-Mura and Minamisoma City to the Ocean ${ }^{20.21}$, we use cutting-edge analytical techniques to document the presence of $\mathrm{Pu}$ and measure the $\mathrm{Pu}$ isotopic abundances and concentrations of four plutonium isotopes $\left({ }^{239} \mathrm{Pu},{ }^{240} \mathrm{Pu},{ }^{241} \mathrm{Pu}\right.$, and $\left.{ }^{242} \mathrm{Pu}\right)$ in recently deposited riverbed sediment collected along rivers draining the most contaminated part of the inland radioactive plume. This study will thereby provide crucial clues on the origin and the fate of plutonium in coastal catchments that were the most affected by the initial radioactive fallout, which may possibly represent a perennial source of plutonium to the Pacific Ocean during the next decades.

\section{Methodology}

Study area and sampling. Fieldwork was conducted in the accessible parts of the Nitta R., Ota R. and Ukedo Rivers draining the main radioactive pollution plume between November 2011 and May 2013 (Fig. 1). Their catchments, covering respectively 271,79 and $425 \mathrm{~km}^{2}$, are dominated by steep forested slopes in upstream mountainous parts (up to $1000 \mathrm{~m}$ elevation), and by paddy fields and built-up areas in valley bottoms and coastal plains ${ }^{20}$. Fine sediment that appeared to have recently deposited (i.e., mud drapes on channel-bed sand) was collected along these three rivers. An additional soil sample was taken in the vicinity of the most contaminated sediment sample to allow for comparison. Samples were dried in an oven at $40^{\circ} \mathrm{C}$ for $72 \mathrm{~h}$, sieved to $2 \mathrm{~mm}$, ground to a fine powder using an agate mortar and stored at room temperature before analysis. Details on the field sampling campaign and strategy are given in a previous publication ${ }^{20}$. For this study, we selected samples to document the Pu contamination of fine sediment deposits along each of the rivers draining the main radioactive contamination plume.

Gamma spectrometry. Radionuclide activities $\left({ }^{134} \mathrm{Cs},{ }^{137} \mathrm{Cs},{ }^{110 \mathrm{~m}} \mathrm{Ag}\right)$ in all samples were determined by gamma spectrometry using very low-background HPGe detectors. All gamma radionuclide activities were expressed in $\mathrm{Bq}$ per $\mathrm{kg}$ of dry weight $\left(\mathrm{Bq} \mathrm{kg}^{-1}\right)$. Counting time of soil and sediment samples varied between $8 \times 10^{4}$ and $200 \times 10^{4}$ s to allow the detection of ${ }^{110 \mathrm{~m}} \mathrm{Ag}$, which was present in much lower activities in the samples $\left(2-2390 \mathrm{~Bq} \mathrm{~kg}{ }^{-1}\right)$ compared to ${ }^{134} \mathrm{Cs}$ and ${ }^{137} \mathrm{Cs}\left(500-1,245,000 \mathrm{~Bq} \mathrm{~kg}^{-1}\right)$. Six samples were selected for further Pu analyses because of their high activities in both ${ }^{134+137} \mathrm{Cs}$ and ${ }^{110 \mathrm{~m}} \mathrm{Ag}$.

Sample preparation and purification procedure for plutonium analysis. $\sim 5$ gram-aliquots of each soil sample were transferred in Pyrex beakers and reduced to ash at $550^{\circ} \mathrm{C}$ for 24 hours in an electric 
furnace to decompose organic matter. During heating, beakers were covered with watch glasses to prevent cross contaminations. After cooling to room temperature, limited amounts of ${ }^{244} \mathrm{Pu}(\sim 100 \mathrm{fg})$ were added to the samples as isotopic dilution tracer for plutonium quantitative analysis. The stock solution of $\sim 1 \mathrm{pg} \cdot \mathrm{g}^{-1}$ used for spiking was prepared by gravimetric dilutions of the mother solution prepared from NBS 131 Certified Reference Material (New Brunswick Laboratory, Argonne, IL, USA). Then, ashes were leached on hot plates with strong acid media in five successive steps: first leaching with fuming $\mathrm{HNO}_{3}(30 \mathrm{ml})$, evaporation to dryness, second leaching with fuming $\mathrm{HNO}_{3}(30 \mathrm{ml})$, evaporation to dryness, third leaching with fuming $\mathrm{HNO}_{3}(30 \mathrm{ml})$ and $\mathrm{H}_{2} \mathrm{O}_{2}(1 \mathrm{ml})$, evaporation to dryness, fourth leaching with concentrated $\mathrm{HCl}(30 \mathrm{ml})$, evaporation to dryness, fifth leaching with $4 \mathrm{M} \mathrm{HCl}(50 \mathrm{ml})$, evaporation to dryness. Samples were not fully digested. At each leaching step, solutions were back flow heated $\left(120-150^{\circ} \mathrm{C}\right)$ for several hours and then evaporated to dryness. All acids used were of analytical grade. Samples were filtered using single-use $0.45 \mu \mathrm{m}$ analytical filter units (Thermo Scientific, Rochester, NY, USA). Plutonium in the soil and sediment samples, and especially the plutonium possibly released by the FDNPP, was assumed to be present in the dissolved fractions. Therefore, only the dissolved fractions of the samples were further processed. Dissolved fractions were then evaporated to dryness and recovered with $30 \mathrm{ml}$ of concentrated $\mathrm{HNO}_{3}$. Adjustment and redox state stabilization of Pu at +IV oxidation state were performed by addition of small amounts of $\mathrm{NaNO}_{2}$ followed by evaporation. Samples were recovered with $30 \mathrm{ml}$ of $8 \mathrm{~N} \mathrm{HNO}_{3}$ just before introduction into the conditioned ion-exchange resin columns. It should be noted that three process blanks were prepared in the same conditions as the samples. No Pu isotopes were detected in the process blanks.

A first Pu purification was performed with a 20-ml column filled with Dowex AG1X8 anion-exchange resin (10 $\mathrm{ml}$ of 50/100 mesh resin at the bottom and $10 \mathrm{ml}$ of 100/200 mesh resin on the top) rinsed twice and conditioned with $8 \mathrm{M} \mathrm{HNO}_{3}$. Further Pu purification is obtained by using a $2 \mathrm{ml}$-column filled with Dowex AG1X4 anion-exchange resin (100-200 mesh). Both resins are washed with $8 \mathrm{M}$ $\mathrm{HNO}_{3}$ (U fraction elution), $10 \mathrm{M} \mathrm{HCl}$ (Th fraction elution) and, finally, with $\mathrm{NH}_{4} \mathrm{I}(1.5 \%)-12 \mathrm{M} \mathrm{HCl}$ solution prepared just before use to elute Pu fraction. Final solutions were evaporated to dryness and recovered with $3 \mathrm{ml}$ of $2 \% \mathrm{HNO}_{3}$ which is the suitable media for ICP-MS measurement. Global Pu recoveries reached an average of $\sim 45 \%$ (between $35 \%$ and $57 \%$ depending on samples).

Mass spectrometry for $\mathrm{Pu}$ atom ratio and concentration measurements. Pu isotopic composition and concentrations were measured with a double-focusing sector field ICP-MS ("Element XR", Thermo-Scientific, Bremen, Germany). The separation of the isotope ion beams is carried out through a double-focusing arrangement, both in angle and energy, by means of an electrostatic sector followed by a magnetic sector. This instrument is equipped with the "jet interface" option, composed of a desolvating module ("Apex", ESI, Omaha, NE, USA), high efficiency cones, and a higher capacity primary pump that decreases vacuum in the interface. This option provides increase in sensitivity by a factor of ten compared to the standard configuration of the instrument (i.e. $\sim 4 \times 10^{7}$ counts $\mathrm{s}^{-1}$ per $\mu \mathrm{g} \mathrm{L}^{-1}$ versus $\sim 4 \times 10^{6}$ counts $\mathrm{s}^{-1}$ per $\mu \mathrm{g} \mathrm{L}^{-1}$ for the standard configuration). Instrumental background is typically $\sim 0.3 \pm 0.2$ count $\mathrm{s}^{-1}$ in the actinide mass range.

The performance of the instrument is daily optimized with respect to sensitivity, short term stability (10 minutes) and background. The instrument is operated in electric scanning by varying the accelerating voltage, with the intensity of the magnetic field set to a fixed value. A Teflon micro- 
concentric nebulizer (“PFA100", ESI, Omaha, NE, USA) was used for sample introduction into the "Apex" desolvating device.

In order to reach high accuracy for isotopic ratio determinations, instrumental mass bias - due to variations in the transmission efficiencies of ions of different masses in the instrument - had to be carefully corrected ${ }^{22}$. This is done by standard bracketing of samples with diluted solutions of NBS U005 (New Brunswick Laboratory, Argonne, IL, USA) and IRMM-184 (IRMM, Geel, Belgium) isotopic standards. The mass bias per mass unit $(\varepsilon)$ is determined according to the linear function: $\varepsilon=\left(R_{\text {certified }} / R_{\text {measured }}-1\right) / \Delta m$, where $\Delta \mathrm{m}$ is the mass difference between the isotopes of interest.

During the analyses, great care must be taken to avoid contamination and memory effects. As a rule, the glassware, the sampler and skimmer cones must be regularly and carefully cleaned to ensure the lowest background and the best sensitivity and stability. Moreover, the "Element XR" ICPMS is located in a clean room, class 1000 , to avoid contamination when handling of the samples. Rinsing blank periods, intended to suppress any memory effect and to avoid cross-contamination by the sample probe, separated the sample measurements. Raw signals were systematically corrected for mass bias, tracer isotopic impurities, peak tailing and ${ }^{238} \mathrm{U}$ hydrides. In order to obtain the most accurate measurement results, raw signals are corrected for polyatomic interferences (mainly $\mathrm{PbO}_{2}$, $\mathrm{IrO}_{3}$, and $\mathrm{HgAr}$ ) that interfere with $\mathrm{Pu}$ isotopes ${ }^{23,24}$. Uncertainty calculations followed

recommendations from the Guide to the expression of Uncertainty in Measurement ${ }^{25}$. Relative standard uncertainties ranged from $3 \%$ to $5 \%$ for the ${ }^{240} \mathrm{Pu} /{ }^{239} \mathrm{Pu}$ ratios, from $6 \%$ to $17 \%$ for the ${ }^{241} \mathrm{Pu} /{ }^{239} \mathrm{Pu}$ ratios, and from $12 \%$ to $48 \%$ for the ${ }^{242} \mathrm{Pu} /{ }^{239} \mathrm{Pu}$ ratios

\section{Results and discussion}

Measured activities for plutonium isotopes, ${ }^{137} \mathrm{Cs}$ and ${ }^{110 \mathrm{~m}} \mathrm{Ag}$ are compiled in Table 1, while measured atom ratios and mass concentration for plutonium are given in Table 2 . All measured plutonium isotopes $\left({ }^{239} \mathrm{Pu},{ }^{240} \mathrm{Pu},{ }^{241} \mathrm{Pu},{ }^{242} \mathrm{Pu}\right)$ were detected in the entire set of samples, although in low activities. Figures 2, 3 and 4 show respectively ${ }^{241} \mathrm{Pu} /{ }^{239} \mathrm{Pu}$ versus ${ }^{240} \mathrm{Pu} /{ }^{239} \mathrm{Pu}$ atom ratios, ${ }^{242} \mathrm{Pu} /{ }^{239} \mathrm{Pu}$ versus ${ }^{240} \mathrm{Pu} /{ }^{239} \mathrm{Pu}$ atom ratios, and ${ }^{241} \mathrm{Pu} /{ }^{239} \mathrm{Pu}$ versus ${ }^{242} \mathrm{Pu} /{ }^{239} \mathrm{Pu}$ atom ratios. Moreover, $\mathrm{Pu}$ measurements conducted on soil samples from 54 locations around the world and reported in the literature ${ }^{7,14,26}$ are also plotted on these graphs. These measurements provide a global baseline for identifying inputs of non-global fallout $\mathrm{Pu}$. All ${ }^{241} \mathrm{Pu} /{ }^{239} \mathrm{Pu}$ ratios were corrected for radioactive decay to the reference date of 15 March 2011, using a half-life of 14.325 years ${ }^{27}$.

${ }^{240} \mathrm{Pu} /{ }^{239} \mathrm{Pu}$ atom ratios. Many studies characterised the Pu content in soil samples due to global fallout associated with the nuclear tests. They showed that isotopic signatures in soils are not uniform, and that variations may be observed depending on distance from nuclear test sites, proportion of stratospheric / tropospheric debris, location in the Southern or Northern hemisphere, etc. As shown in the literature ${ }^{26}$, even samples collected at the same time and at the same location show significant heterogeneities that may be attributed to different amounts of the tropospheric fallout component (the ${ }^{240} \mathrm{Pu} /{ }^{239} \mathrm{Pu}$ signature for tropospheric fallout does usually not exceed half that of stratospheric fallout). In this context, fallout isotopic signatures are better represented by "mixing lines", rather than by averages ${ }^{26}$. This allows for a better depiction of regional variations of stratospheric fallout inventories compared to tropospheric fallout inventories. The lowest and 
highest ${ }^{240} \mathrm{Pu} /{ }^{239} \mathrm{Pu}$ ratios amount respectively to $\sim 0.062$ (Eureka, Nevada, USA - an area close to the Nevada Test Site) and $\sim 0.205$ (Punta Arenas, Chile) ${ }^{26}$. The average ${ }^{240} \mathrm{Pu} /{ }^{239} \mathrm{Pu}$ atom ratio for the Northern hemisphere is $0.176 \pm 0.007$ (standard-uncertainty, 1 SD). Regarding Japan, several authors published values representative of the global fallout in Japanese soils. Kelley et al. ${ }^{26}$ reported ${ }^{240} \mathrm{Pu} /{ }^{239} \mathrm{Pu}$ of respectively $0.1755 \pm 0.0024$ and $0.1765 \pm 0.0022$ in two soil samples from Tokyo and Sapporo. Muramatsu et al. (2003) also reported ${ }^{240} \mathrm{Pu} /{ }^{239} \mathrm{Pu}$ atoms ratios measured in Japanese forest soils and they ranged from $0.155 \pm 0.003$ (1 SD) to $0.194 \pm 0.005$ (1 SD) (average value $0.176 \pm 0.011,1$ SD) with an extremely low value of $0.037 \pm 0.002$ for a sample collected at Nagasaki ${ }^{28}$, a ratio lower than the lowest ratio of 0.062 measured in a soil sample from Eureka (Nevada, USA). Zhang et al. ${ }^{29}$ measured a ratio of $0.1922 \pm 0.0044$ in a composite reference material prepared from soil samples collected at 14 stations in Japan between 1963-1979. In the sediments of the Western North Pacific and its marginal seas, ${ }^{240} \mathrm{Pu} /{ }^{239} \mathrm{Pu}$ atom ratios ranging from 0.15 to 0.28 were measured before the FDNPP accident ${ }^{18,19}$. Average Pu ratios in the Northern Hemisphere and Pu ratios measured for Japanese soils due to global fallout are also reported in Table S2. However, since the FDNPP accident, several authors measured ${ }^{240} \mathrm{Pu} /{ }^{239} \mathrm{Pu}$ atom ratios significantly higher than the global fallout ratios. Values comprised between 0.286 and 0.365 were measured by Yamamoto at al. ${ }^{17}$ in radioactive roadside dust samples collected in the same area. It appears from Figures 2 and 3 that for all of the samples but FNL 034B, ${ }^{240} \mathrm{Pu} /{ }^{239} \mathrm{Pu}$ atom ratios measured in this study (red plan circles) are not significantly different from the published global world baseline for fallout Pu (blue empty circles). Actually, ${ }^{240} \mathrm{Pu} /{ }^{239}$ Pu measured in this study in 5 out of the 6 samples collected in the vicinity of Fukushima are comprised between 0.150 (FOL 250) and 0.203 (FOL 255) (Table 2). Sample FOL 250 shows a significantly lower ${ }^{240} \mathrm{Pu} /{ }^{239} \mathrm{Pu}$ atomic ratio than the average ratio reported in soils of the Northern hemisphere and in Japanese soils analyzed before the accident (see excerpt in Fig. 2).

${ }^{241} \mathrm{Pu} /{ }^{239} \mathrm{Pu}$ and ${ }^{242} \mathrm{Pu} /{ }^{239} \mathrm{Pu}$ atom ratios. Only a few values are available regarding the ${ }^{241} \mathrm{Pu} /{ }^{239} \mathrm{Pu}$ and ${ }^{242} \mathrm{Pu} /{ }^{239} \mathrm{Pu}$ atom ratios due to global fallout (see Table S2). Average values for the Northern Hemisphere is $0.00113 \pm 0.00008$ ( $1 \mathrm{SD}$ ) for the ${ }^{241} \mathrm{Pu} /{ }^{239} \mathrm{Pu}$ atom ratios and $0.00387 \pm 0.00071$ (1 SD) for the ${ }^{242} \mathrm{Pu} /{ }^{239} \mathrm{Pu}$ ratios ${ }^{26}$. In contrast, ${ }^{241} \mathrm{Pu} /{ }^{239} \mathrm{Pu}$ atom ratios measured in the 6 samples analyzed in this study $(0.0017-0.0884)$ were systematically higher than the corresponding atom ratios attributed to the global fallout (Fig. 2 and 4). This demonstrates that the ${ }^{241} \mathrm{Pu} /{ }^{239} \mathrm{Pu}$ atom ratio is a much more sensitive indicator of the presence of Pu from nuclear spent fuels like the ones originating from FDNPP than the ${ }^{240} \mathrm{Pu} /{ }^{239} \mathrm{Pu}$ ratio. Actually, most of the ${ }^{241} \mathrm{Pu}$ from the global fallout plutonium has disappeared because of its relatively short radioactive period (14.325 years). To a lesser extent, the ${ }^{242} \mathrm{Pu} /{ }^{239} \mathrm{Pu}$ atom ratio is also a valuable indicator of FDNPP-derived $\mathrm{Pu}$ (see Figures 3 and 4). Even though the ${ }^{242} \mathrm{Pu} /{ }^{239} \mathrm{Pu}$ ratios measured in this study have fairly large uncertainties, most of them (with exception of FNS 140 and FOL 250) are higher than the global fallout signature and corresponding ratios measured in Japanese soils ${ }^{26}$.

Origin and fate of the detected Pu. Overall, our results demonstrate that $\mathrm{Pu}$ isotopic compositions similar to the ones found in roadside dust samples outside the $20-\mathrm{km}$ exclusion zone in litate-Mura and Minamisoma municipalities ${ }^{17}$ could also be measured in fresh riverbed sediment deposits. They confirm that Pu originating from FDNPP could be transported relatively long distances from the damaged power plant and is already being supplied to coastal rivers, thereby representing a potential source of Pu to the Ocean (Fig. S1). In the main radioactive contamination plume where the highest radiocesium activities were found, the highest plutonium concentrations were measured, i.e. in samples FNS 140, FOL 250, and FEL 385 . However, plutonium in these samples is mainly originating 
from global fallout as showed by their isotope ratios close to the global fallout signal in Japanese soils. The relatively low ${ }^{240} \mathrm{Pu} /{ }^{239} \mathrm{Pu}$ ratio $(0.150 \pm 0.005,1 \mathrm{SD})$ of sample FOL 250 is very interesting, as its ${ }^{239} \mathrm{Pu}$ abundance is clearly higher than the one of the other samples. The sample FOL 250 could therefore contain Pu from another source than one or several of the damaged reactors from FDNPP, which would have higher ${ }^{239} \mathrm{Pu}$ abundance than the reported global fallout measured in Japanese soils ${ }^{26,28,29}$. However, the ${ }^{240} \mathrm{Pu} /{ }^{239} \mathrm{Pu}$ ratio of this sample remains within the range of ratios reported for global fallout (Table S2).

In the coastal plains where initial cesium fallout was comparatively much lower, total Pu concentrations are also lower, although the Pu atom ratios show a clear FDNPP signature, especially higher ${ }^{241} \mathrm{Pu}$ and ${ }^{242} \mathrm{Pu}$ isotopic concentrations. This result would corroborate the findings previously published based on the spatial pattern of ${ }^{110 \mathrm{~m}} \mathrm{Ag}:{ }^{137} \mathrm{Cs}$ ratio measured in soils after the Fukushima accident (Fig. S1) ${ }^{20,30}$. However, the outlying atom ratios found in sample FNL034B - which is also the most contaminated in both plutonium and radiocesium - are rather surprising. This sample, collected in Nitta River headwaters, is not located within the main radioactive plume, but in its prolongation to the northwest. As this zone is currently being decontaminated, more analyses should be conducted to better understand the Pu isotopic atom ratio patterns and distribution across this area. Transport of Pu to longer distances in Fukushima than in Chernobyl may be explained by the different accidental conditions that prevailed at both sites. In Chernobyl, the Pu bearing particles were larger because of the graphite fires, which likely explains that they deposited at a shorter distance from the power plant ${ }^{1}$.

Respective proportions of FDNPP Pu and of global fallout Pu. It is possible to calculate for each analyzed sample the fraction of Pu which originates from the FDNPP, using isotopic abundances. Values taken into account for isotopic compositions of Pu from FDNPP reactors were respectively taken from previous studies ${ }^{6,10,12,13}$ (see Table S1). Abundance for the global fallout was the one measured by Kelley et al. ${ }^{26}$ for a soil sample collected in Tokyo. The fraction of Pu from FDNPP in a given sample $\left(\mathrm{X}_{\mathrm{FD}, \mathrm{i}}\right)$ may be calculated as follows for any ${ }^{\mathrm{i}} \mathrm{Pu}$ isotope $(\mathrm{i}=239,240,241$, and 242$)$ :

$X_{F D, i}=\frac{A\left({ }^{i} P u\right)_{M e S}-A\left({ }^{i} P u\right)_{G F}}{A\left({ }^{i} P u\right)_{F D}-A\left({ }^{i} P u\right)_{G F}}$

Where $A\left({ }^{i P u}\right)_{M e s}, A\left({ }^{i P u}\right)_{G F}$, and $A\left({ }^{i} P u\right)_{F D}$ are the ${ }^{i} P u$ isotopic abundances respectively in the $\mathrm{Pu}$ measured in the sample, from the global fallout, and from FDNPP. The standard uncertainty on $X_{F D, i}$ is calculated by using the propagation error formula.

Results obtained with the isotope ${ }^{241} \mathrm{Pu}$ are the most precise and are given in Table S3. Fractions of Pu originating from FDNPP calculated using ${ }^{240} \mathrm{Pu}$ and ${ }^{241} \mathrm{Pu}$ isotopes remained in relatively good agreement. However, results obtained with the ${ }^{240} \mathrm{Pu}$ isotopes have high standard uncertainties, especially for the samples for which both ${ }^{240} \mathrm{Pu} /{ }^{239} \mathrm{Pu}$ ratios are very close. Negative values were even obtained for FNS 140 and FOL 250 samples using the ${ }^{240} \mathrm{Pu}$ abundances as ${ }^{240} \mathrm{Pu} /{ }^{239} \mathrm{Pu}$ atom ratios in both samples were slightly lower than the value taken into account for characterizing the Pu isotopic composition of global fallout. Calculations with the ${ }^{241} \mathrm{Pu}$ abundances were performed with a higher precision and were referred to hereafter. If we consider the isotopic compositions derived from the values published by Nishihara et al. ${ }^{12}$, the fractions of Pu from FDNPP in the analyzed soils range from $\sim 1 \%$ for FNS 140 and FOL 250 samples to $60 \%$ for FNL 034B sample. Again, this result is rather 
surprising as the FNL 034B sampling site is the farthest from FDNPP ( 45 km). However, these results are relatively consistent with previous findings. Schwantes et al. ${ }^{10}$ observed that vented plutonium from Units 1 and 3 accounts for $\sim 16 \%$ of the total plutonium present in surface soil located at up to $45 \mathrm{~km}$ from the source. Yamamoto et al. ${ }^{14}$ calculated a proportion of FDNPP-originating Pu comprised between 2-44 \% in surface soils collected $\sim 25 \mathrm{~km} \mathrm{NW}$ from FDNPP (litate-Mura). In addition, Zheng et al. ${ }^{15}$ calculated that the percentage of Fukushima-derived Pu was $87 \%$ is surface soil samples collected in the J-village, $20 \mathrm{~km}$ south of FDNPP.

Overall, the additional Pu activity supplied by FDNPP accident to the soils and sediment of the region remains very low. However, the sample characterized by the Pu isotopic composition which is the closest to the global fallout signature - and which contains thus the lowest FDNPP Pu contribution is also the one with the highest Pu concentration (FNS 140, $490 \pm 87 \mathrm{pg} \cdot \mathrm{g}^{-1}$ ). Total ${ }^{239+240+241+242} \mathrm{Pu}$ activity concentrations in the six analyzed soil and riverine sediment samples range from 2.1 (FOL 250 and FNS 140) to $20.6 \mathrm{~Bq} \mathrm{~kg}^{-1}$ dry weight (FNL $034 \mathrm{~B}$ ). ${ }^{238} \mathrm{Pu}$ activity was not considered, but its inclusion would not significantly modify these figures. It should be noted that the most part of this activity is due to the relatively short-lived ${ }^{241} \mathrm{Pu}$ isotope. Overall, the ${ }^{239+240} \mathrm{Pu}$ activity concentrations are between 0.16 and $1.56 \mathrm{~Bq} \mathrm{~kg}^{-1}$ dry weight, within the range of the typical global fallout ${ }^{239+240} \mathrm{Pu}$ activity of 0.15 to $4.31 \mathrm{~Bq} \mathrm{~kg}^{-1}$ dry weight reported in the literature ${ }^{31} .{ }^{241} \mathrm{Pu}$ activities measured in the samples range from 1.2 to $17.7 \mathrm{~Bq} \mathrm{~kg}^{-1}$, in the same range as the high ${ }^{241} \mathrm{Pu}$ activities (from 4.5 to 34.8 $\mathrm{Bq} \mathrm{kg}{ }^{-1}$ dry weight) measured previously in surface soils and litters collected in the vicinity of FDNPP $^{15}$.

Future studies should focus on analyzing Pu isotope and atom ratio values on a large set of soils from the area located to the northwest of the exclusion zone in order to better understand its spatial distribution across the area and the succession of events (burn-up, release of radionuclides, etc.) that occurred at FDNPP in March 2011 and their consequences on Pu dispersion in the environment. Furthermore, similar analyses should be conducted on a larger set of river sediment samples collected in coastal rivers draining this area as this study showed their potential delivery to the Ocean. Our results show that the high ${ }^{241} \mathrm{Pu} /{ }^{239} \mathrm{Pu}$ atom ratio of the Fukushima accident sourced-Pu may particularly provide a relevant tracer of continental-originating material from Fukushima Prefecture to the Pacific Ocean.

\section{Associated content}

Supporting information. Figure displaying the location of the analyzed samples on a map of ${ }^{110 \mathrm{~m}} \mathrm{Ag}$ : ${ }^{137} \mathrm{Cs}$ activity ratio in soils of Fukushima Prefecture, and Tables detailing the Pu isotopic composition used for calculation of the fraction of Pu from FDNPP in the analyzed soil samples (Table S1) and the results of Pu isotopic measurements carried out on Japanese soil samples or atmospheric deposition samples in Japan (Table S2). This material is available free of charge via the Internet at http://pubs.acs.org.

\section{Author information}

\section{Corresponding authors}

*Tel: +33-1-69-82-35-20 (O.Evrard), +33-1-69-26-49-17 (F. Pointurier); e-mail: olivier.evrard@Isce.ipsl.fr (O. Evrard), fabien.pointurier@cea.fr (F. Pointurier). 


\section{Author contributions}

O.E., F.P. and Y.O. conceived the study. Fieldwork and sampling collection was conducted by O.E., C.C., H.L., I.L. and P.B. Then, O.E., H.L., I.L. and P.B. processed samples and conducted gamma spectrometry analyses, whereas plutonium analyses were performed by F.P., A.H. and A.C.P. The manuscript was written by O.E. and F.P., and was reviewed by Y.O., C.C., H.L., I.L., J.P.L., P.B. and S.A.

\section{Acknowledgements}

This work has been supported by ANR and JST in the framework of the joint TOFU ANR Flash/J-RAPID Franco-Japanese project (ANR-11-JAPN-001), the French AMORAD project (ANR-11-RSNR-0002), and by CEA (Direction des Relations Internationales) and UVSQ (Bonus de Qualité Internationale) grants. The authors are grateful to CEA/SPR Saclay (S. Scapolan, S. Brun) for conducting preliminary alpha spectrometry analyses. Fieldwork assistance by K. Hisadome, F. Kono, H. Kato was also greatly appreciated. The authors thank four anonymous reviewers whose comments helped improve the manuscript. 


\section{References}

1. Steinhauser, G.; Brandl, A.; Johnson, T.E. Comparison of the Chernobyl and Fukushima nuclear accidents: A review of the environmental impacts. Sci. Total Environ., 2014, 470-471, 800-817.

2. Le Petit, G.; et al. Analysis of radionuclide releases from the Fukushima Dai-ichi Nuclear Power Plant accident, Part I. Pure Appl. Geophys., 2014, 171, 629-644.

3. Achim, P.; et al. Analysis of radionuclide releases from the Fukushima Dai-ichi Nuclear Power Plant accident, Part II. Pure Appl. Geophys., 2014, 171, 645-667.

4. Kato, H.; Onda, Y.; Teramage, M. Depth distribution of ${ }^{137} \mathrm{Cs}$, ${ }^{134} \mathrm{Cs}$, and ${ }^{131} \mathrm{I}$ in soil profile after Fukushima Dai-ichi Nuclear Power Plant Accident. J. Environ. Radioact., 2012, 111, 59-64.

5. Kamada, N.; Saito, O.; Endo, S.; Kimura, A.; Shizuma, K. Radiation doses among residents living $37 \mathrm{~km}$ northwest of the Fukushima Dai-ichi Nuclear Power Plant. J. Environ. Radioact., 2012, 110, 84-89.

6. Kirchner, G.; Bossew, P.; De Cort, M. Radioactivity from Fukushima Dai-ichi in air over Europe; part 2: what can it tell us about the accident? J. Environ. Radioact., 2012, 114, 35-40.

7. Hardy, E.P., Krey, P.W., Volchok, H.L., Global inventory and distribution of fallout plutonium, Nature, 1973, 241, 444-445.

8. Krey, P.W.; Hardy, E.P.; Pachuki, C.; Rourke, F.; Coluzza, J.; Benson, W.K. Mass isotopic composition of global fallout plutonium in soil: Transuranium nuclides in the environment, Proceedings of a symposium jointly organized by (USERDA/ IAEA symposium proceedings, San Francisco, 17-21/11/1975), STI/PUB/410, IAEA, 1976.

9. Ministry of Education, Culture, Sports Science and Technology (MEXT). Results of the Nuclide Analysis of Plutonium and Strontium by MEXT. http://radioactivity.nsr.go.jp/en/contents/5000/4167/24/1750 093014.pdf, (2011) Date of access: 01/04/2014.

10. Schwantes, J.M.; Orton, C.R.; Clark, R.A. Analysis of a nuclear accident: Fission and activation product releases from the Fukushima Dai-ichi nuclear facility as remote indicators of source identification, extent of release, and state of damaged spent nuclear fuel. Environ. Sci. Technol., 2012, 46, 8621-8627.

11. Schneider, S.; et al. Plutonium release from Fukushima Dai-ichi fosters the need for more detailed investigations. Sci. Rep., 2013, 3, 2988.

12. Nishihara, K., Iwamoto, H., Suyama, K., Estimation of fuel compositions in Fukushima-Daiichi Nuclear Power Plant, 2012, JAEA-Data/Code No. 2012-018.

13. Zheng, J.; Tagami, K.; Uchida, S. Release of plutonium isotopes into the environment from the Fukushima Dai-ichi Nuclear Power Plant accident: what is known and what needs to be known. Environ. Sci. Technol., 2013, 47, 9584-9595.

14. Yamamoto, M.; et al. Early survey of radioactive contamination in soil due to the Fukushima Dai-ichi Nuclear Power Plant accident: with emphasis on Pu analysis. Geochem. J., 2012, 46, 341-353.

15. Zheng, J.; et al. Isotopic evidence of plutonium release into the environment from the Fukushima-DNPP accident. Sci. Rep., 2012, 2, 304.

16. Sakaguchi, A.; et al. Isotopic determination of $U, P u$ and $C s$ in environmental waters following the Fukushima Dai-ichi Nuclear Power Plant accident. Geochem. J., 2012, 46, 355-360. 
17. Yamamoto, M.; et al. Isotopic $\mathrm{Pu}, \mathrm{Am}$ and $\mathrm{Cm}$ signatures in environmental samples contaminated by the Fukushima Dai-ichi Nuclear Power Plant accident. J. Environ. Radioact., 2014, 132, 31-46.

18. Zheng, J.; Aono, T.; Uchida, S.; Zhang, J.; Honda, M.C. Distribution of Pu isotopes in marine sediments in the pacific $30 \mathrm{~km}$ off Fukushima after the Fukushima Dai-ichi nuclear power plant accident. Geochem. J., 2012, 46, 361-369.

19. Bu, W.T.; et al. Determination of plutonium isotopes in marine sediments off the Fukushima coast following the Fukushima Dai-ichi Nuclear Power Plant accident. Biogeosciences Discuss., 2013, 10, 643-680.

20. Chartin, C.; et al. Tracking the early dispersion of contaminated sediment along rivers draining the Fukushima radioactive pollution plume. Anthropocene, 2013, 1, 23-34.

21. Evrard, O.; et al. Evolution of radioactive dose rates in fresh sediment deposits along rivers draining Fukushima contamination plume. Sci. Rep., 2013, 3, 3079.

22. Pointurier, F.; Baglan, N.; Hémet, P. Ultra low-level measurements of actinides by sector field ICP-MS. Applied Rad. Isot., 2004, 60, 561-566.

23. Pointurier, F.; Hémet, P.; Hubert, A. Assessment of plutonium measurement in the femtogram range by ICP-MS; correction from interfering polyatomic species. J. Anal. At. Spectrom., 2008, 23, 104-112.

24. Pointurier, F.; Hubert, A.; Fauré, A.L.; Hémet, P.; Pottin, A.C. Polyatomic interferences in plutonium determination in the femtogram range by double-focusing sector-field ICP-MS, J. Anal. At. Spectrom., 2011, 26, 1474-1480.

25. Guide to the expression of Uncertainty in Measurement ('GUM', International Organization for Standardization, ISBN 92-67-10188-9, 1995).

26. Kelley, J.M.; Bond, L.A.; Beasley, T.M., Global distribution of Pu isotopes and ${ }^{237}$ Np, Sci. Total. Env., 1999, 237/238, 483-500.

27. Wellum, R., Verbruggen, A., Kessel,R., A new evaluation of the half-life of ${ }^{241} \mathrm{Pu}$, J. Anal. Atom. Spectrom., 2009, 24, 801-807.

28. Muramatsu, Y.; Yoshida, S.; Tanaka, A. Determination of Pu concentration and its isotope ratio in Japanese soils by HR-ICP-MS, J. Radioanal. Nucl. Chem., 2003, 255, 477-480.

29. Zhang, Y., Zheng, J., Yamada, M., WU, F., Igarashi, Y., Hirose, K., Characterization of Pu concentration and its isotopic composition in a reference fallout material, Sci. Total Environ. 2010, 408, 1139-1144.

30. Lepage, H.; Evrard, O.; Onda, Y.; Patin, J.; Chartin, C.; Lefèvre, I.; Bonté, P.; Ayrault, S. Environmental mobility of ${ }^{110 \mathrm{~m}} \mathrm{Ag}$ : lessons learnt from Fukushima accident (Japan) and potential use for tracking the dispersion of contamination within coastal catchments. J. Environ. Radioact., 2014, 130, 44-55. 
Figures

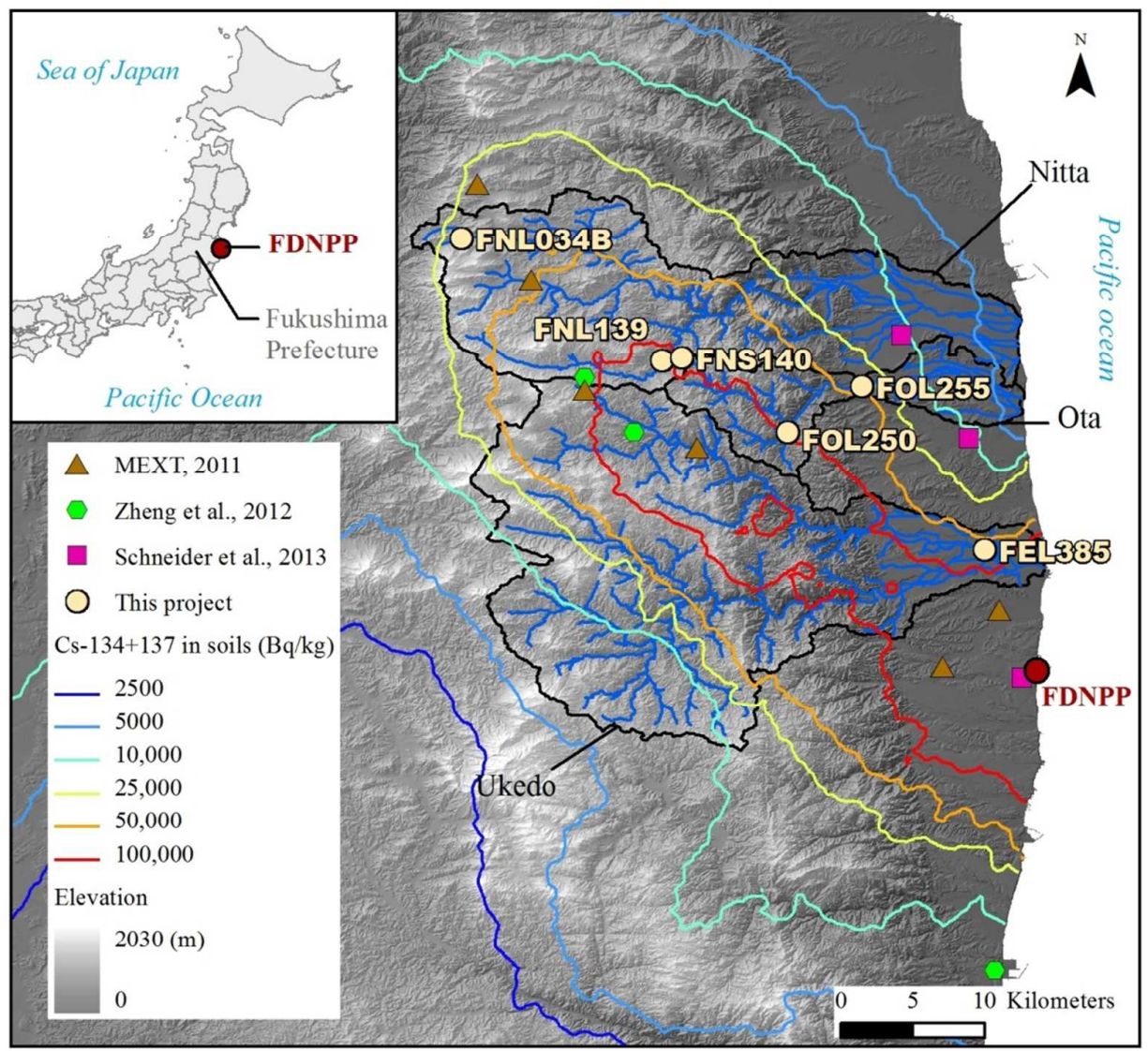

Figure 1. Location of the main inland radiocesium contamination plume in northeastern Japan (colored lines), the analyzed samples (white dots), and samples analyzed in other studies in which plutonium was detected (colored dots).

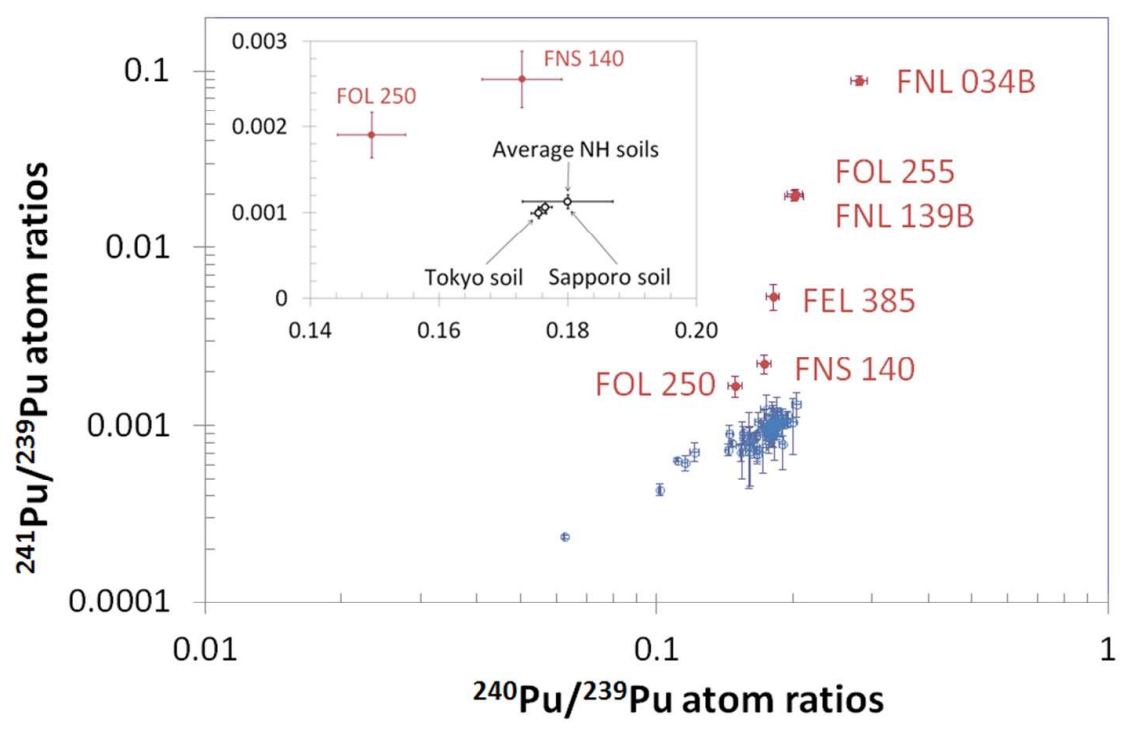


Figure 2. Plot of the ${ }^{241} \mathrm{Pu} /{ }^{239} \mathrm{Pu}$ atom ratios versus the ${ }^{240} \mathrm{Pu} /{ }^{239} \mathrm{Pu}$ atom ratios measured in the frame of this study (red plain circles) and by Hardy et al. ${ }^{7}$, Krey et al. ${ }^{8}$, and by Kelley et al. ${ }^{26}$ (blue empty circles). Uncertainties are standard uncertainties $(\mathrm{k}=1) .{ }^{241} \mathrm{Pu} /{ }^{239} \mathrm{Pu}$ ratios are corrected from radioactive decay to the 15 March 2011. Note that log scales are used for both axes. Excerpt: zoom for FOL 250 and FNS 140 samples and previously published data for Japanese soils ${ }^{22}$ and for average Northern Hemisphere soils (linear scale) ${ }^{22}$.

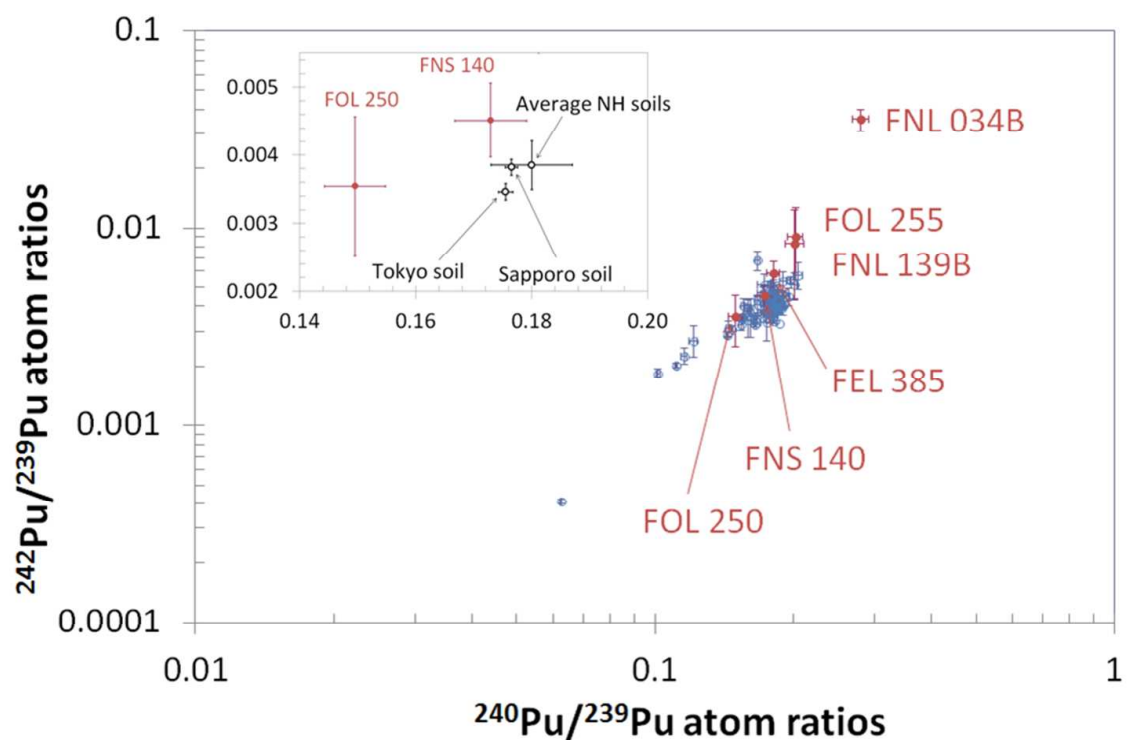

Figure 3. Plot of the ${ }^{242} \mathrm{Pu} /{ }^{239} \mathrm{Pu}$ atom ratios versus the ${ }^{240} \mathrm{Pu} /{ }^{239} \mathrm{Pu}$ atom ratios measured in the frame of this study (red plain circles) and by Hardy et al. ${ }^{7}$, Krey et al. ${ }^{8}$, and by Kelley et al. ${ }^{26}$ (blue empty circles). Uncertainties are standard uncertainties $(\mathrm{k}=1)$. Note that log scales are used for both axes. Excerpt: zoom for FOL 250 and FNS 140 samples and previously published data for Japanese soils ${ }^{22}$ and for average Northern Hemisphere soils (linear scale) ${ }^{22}$.

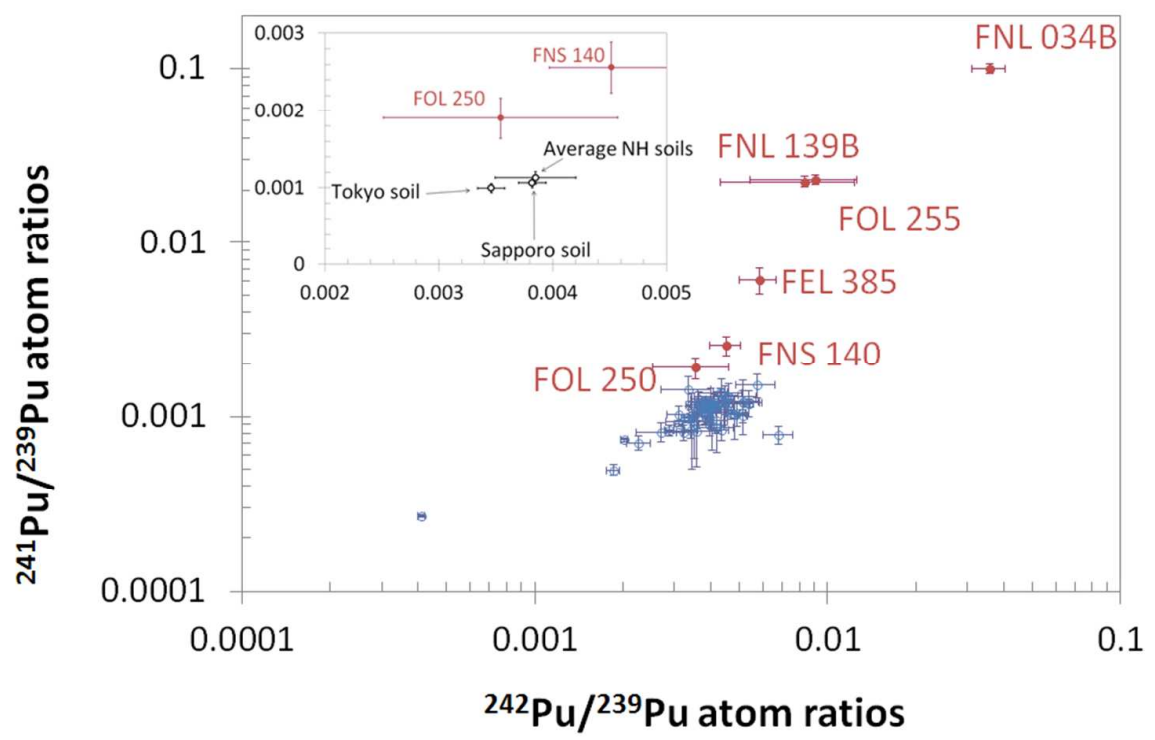


Figure 4. Plot of the ${ }^{241} \mathrm{Pu} /{ }^{239} \mathrm{Pu}$ atom ratios versus the ${ }^{242} \mathrm{Pu} /{ }^{239} \mathrm{Pu}$ atom ratios measured in the frame of this study (red plain circles) and by Hardy et al. ${ }^{7}$, Krey et al. ${ }^{8}$, and by Kelley et al. ${ }^{26}$ (blue empty circles). Uncertainties are standard uncertainties $(\mathrm{k}=1) .{ }^{241} \mathrm{Pu} /{ }^{239} \mathrm{Pu}$ ratios are corrected from radioactive decay to the 15 March 2011. Note that log scales are used for both axes.

\section{Tables}

Table 1. Activity concentrations in radionuclides in the analyzed samples. ${ }^{241} \mathrm{Pu}$ activities are corrected from radioactive decay to 15 March 2011. Uncertainties are standard-uncertainties (given with a coverage factor of 1). Pu isotopic concentration activities are given in Bq per kg of dry weight material.

\begin{tabular}{cccccccc}
\hline Sample & Date & $\begin{array}{c}{ }^{239} \mathrm{Pu} \\
\left(\mathrm{Bq} \cdot \mathrm{kg}^{-1}\right)\end{array}$ & $\begin{array}{c}{ }^{240} \mathrm{Pu} \\
\left(\mathrm{Bq} \cdot \mathrm{kg}^{-1}\right)\end{array}$ & $\begin{array}{c}{ }^{241} \mathrm{Pu} \\
\left(\mathrm{Bq} \cdot \mathrm{kg}^{-1}\right)\end{array}$ & $\begin{array}{c}{ }^{242} \mathrm{Pu} \\
\left(\mathrm{Bq} \cdot \mathrm{kg}^{-1}\right)\end{array}$ & $\begin{array}{c}{ }^{137} \mathrm{Cs} \\
\left(\mathrm{Bq} \cdot \mathrm{kg}^{-1}\right)\end{array}$ & $\begin{array}{c}{ }^{110 m} \mathrm{Ag} \\
\left(\mathrm{Bq} \cdot \mathrm{kg}^{-1}\right)\end{array}$ \\
\hline FNL 034B & Nov. 2011 & $0.121 \pm 0.013$ & $0.125 \pm 0.013$ & $20.3 \pm 2.4$ & $0.00027 \pm 0.00005$ & $715780 \pm 360$ & $3090 \pm 120$ \\
FNL 139B & April 2012 & $0.094 \pm 0.010$ & $0.069 \pm 0.008$ & $3.5 \pm 0.9$ & $0.00005 \pm 0.00003$ & $172370 \pm 160$ & $590 \pm 70$ \\
FNS 140 & April 2012 & $0.954 \pm 0.098$ & $0.603 \pm 0.062$ & $4.1 \pm 0.7$ & $0.00027 \pm 0.00004$ & $188450 \pm 200$ & $1040 \pm 100$ \\
FOL 250 & Nov. 2012 & $0.444 \pm 0.046$ & $0.243 \pm 0.025$ & $1.4 \pm 0.3$ & $0.00010 \pm 0.00003$ & $64200 \pm 200$ & $650 \pm 140$ \\
FOL 255 & Nov. 2012 & $0.118 \pm 0.012$ & $0.088 \pm 0.009$ & $4.5 \pm 0.6$ & $0.00007 \pm 0.00003$ & $116420 \pm 340$ & $600 \pm 220$ \\
FEL 385 & May 2013 & $0.497 \pm 0.051$ & $0.330 \pm 0.034$ & $5.1 \pm 1.0$ & $0.00018 \pm 0.00003$ & $102430 \pm 380$ & $400 \pm 240$ \\
\hline
\end{tabular}

Table 2. Pu concentration and atom ratios measured in this study. ${ }^{241} \mathrm{Pu} /{ }^{239} \mathrm{Pu}$ ratios are corrected from radioactive decay to 15 March 2011. Uncertainties are standard-uncertainties (given with a coverage factor of 1 ). Pu concentrations are given in pg per kg of dry weight material.

\begin{tabular}{ccccc}
\hline Sample & $\begin{array}{c}{ }^{240} \mathrm{Pu} /{ }^{239} \mathrm{Pu} \\
\text { atom ratio }\end{array}$ & $\begin{array}{c}{ }^{241} \mathrm{Pu} /{ }^{239} \mathrm{Pu} \\
\text { atom ratio }\end{array}$ & $\begin{array}{c}{ }^{242} \mathrm{Pu} /{ }^{239} \mathrm{Pu} \\
\text { atom ratio }\end{array}$ & $\mathrm{Pu}\left(\mathrm{pg} \cdot \mathrm{kg}^{-1}\right)^{\mathrm{a}}$ \\
\hline FNL 034B & $0.281 \pm 0.012$ & $0.1006 \pm 0.0065$ & $0.0356 \pm 0.0045$ & $74 \pm 12$ \\
FNL 139B & $0.201 \pm 0.010$ & $0.0224 \pm 0.0015$ & $0.0083 \pm 0.0040$ & $50 \pm 9$ \\
FNS 140 & $0.173 \pm 0.006$ & $0.0026 \pm 0.0003$ & $0.0045 \pm 0.0005$ & $490 \pm 87$ \\
FOL 250 & $0.150 \pm 0.005$ & $0.0019 \pm 0.0003$ & $0.0035 \pm 0.0010$ & $223 \pm 41$ \\
FOL 255 & $0.203 \pm 0.008$ & $0.0229 \pm 0.0014$ & $0.0090 \pm 0.0036$ & $63 \pm 11$ \\
FEL 385 & $0.181 \pm 0.006$ & $0.0061 \pm 0.0010$ & $0.0058 \pm 0.0009$ & $258 \pm 45$ \\
\hline
\end{tabular}


Investigating the potential sediment-borne Pu supply from Fukushima coastal rivers to the Pacific Ocean

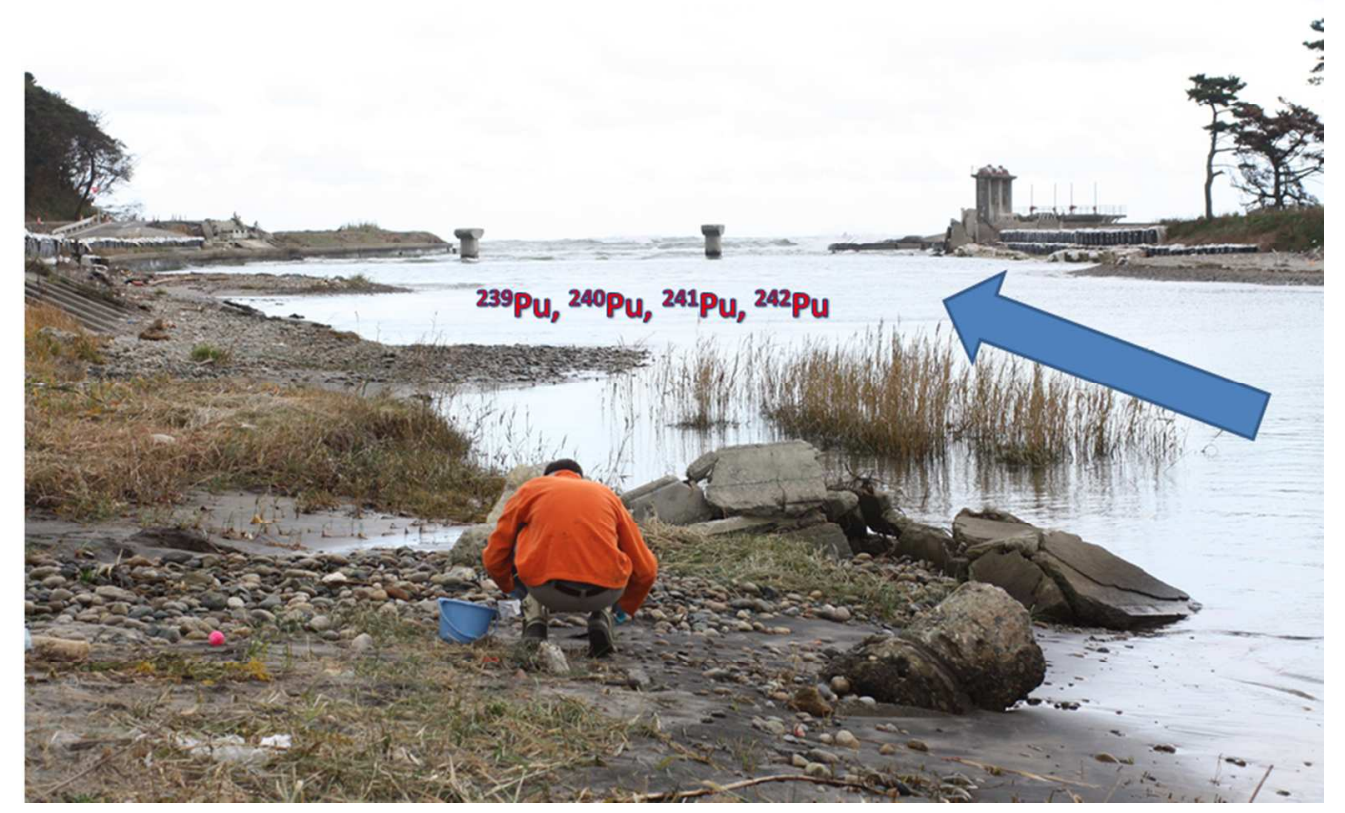

$254 \times 190 \mathrm{~mm}(96 \times 96 \mathrm{DPI})$ 